\section{Discovery of the Genus Ceroptres (Hymenoptera: Cynipidae) in Japan and Korea ${ }^{1}$}

\author{
Yoshihisa ABE \\ Laboratory of Entomology, Faculty of Agriculture, Kyoto \\ Prefectural University, Kyoto 606, Japan
}

(Received 14 May 1996)

(Accepted 18 October 1996)

Key words: Cynipidae, Ceroptres, inquiline gall wasp, new species

Members of the genus Ceroptres are inquiline gall wasps that are dependent on cynipid galls on Quercus spp. (RonQUist, 1994). Species of Ceroptres are morphologically characterized by having: (1) striae radiating from the mouth onto the face; (2) two distinct submedial pits on the pronotum; (3) closed radial cell of forewing; and (4) metasomal tergites 2 and 3 which are not fused. They are distributed in the Holarctic Region and 26 species have been recorded, but no species have been reported from Japan and Korea. Mr. H. Masuda, Dr. K. Morimoto and Dr. C.Y. LEE offered me Ceroptres specimens emerging from galls produced by the Andricus mukaigawae complex (family: Cynipidae), and I independently obtained additional specimens. I examined these Ceroptres specimens from Japan and Korea and found that they were distinct from other members of this genus. Hence I describe a new Ceroptres species in the present paper. The holotype is deposited in the collection of the Laboratory of Entomology, Kyoto Prefectural University. Before going further, I would like to express my sincere thanks to Mr. H. MASUDA, Dr. K. MoRimoto and Dr. C.Y. LeE for their kindness in providing invaluable material. Thanks are also due to anonymous referees for comments.

\section{DESCRIPTION}

Ceroptres masudai n. sp. (Fig. 1)

Female. Forewing length $1.6-2.7 \mathrm{~mm}$. Head and mesosoma black, metasoma dark brown to black; antennae, mandibles, palpi, tegulae and legs brown to brownish yellow.
Head wider than mesosoma in dorsal view. Antenna 12-segmented; relative lengths of flagellar segments 1-10: 11, 12, 11, 11, 10, 10, 9, 8, 8, 15. Vertex with scattered pubescence, frons and genae pubescent. Face with two vertical, parallel and weakly-bowed carinae from the ventral margin of the antennal sockets; striae radiating from mouth outside of the carinae.

Mesosoma pubescent except for the middle of the mesopleuron. Pronotal plate distinct, two foveae on either side of medial bridge open. Notaulices complete, but weak near the anterior margin of mesoscutum; anterior parallel and lateral lines present; median line reaching one third of mesoscutum. Mesopleural suture absent. Scutellum punctatereticulate. Propodeal carinae wider in lower portion.

Radial cell of forewing closed on wing margin, wing surface closely ciliate.

Metasoma smooth, shining; lateral portions of second tergite pubescent anteriorly, sparsely haired posteriorly; lateral portions of third tergite with a few hairs; dorsal portion of seventh tergite with scattered hairs. Fourth-seventh tergites and post-dorsal portion of third tergite with small punctures; each small puncture bearing a very fine seta.

Male. Differs from female as follows. Forewing length $1.9-2.3 \mathrm{~mm}$. Antenna 15 -segmented; relative lengths of flagellar segments 1-13: 12, 13, 12, 12, 12, $11,10,10,9,8,8,7,9$. Metasomal tergite 2 with sparse hairs on lateral portions; lateral portions of third tergite with no or few hairs.

Holotype 우, Makioka-cho, Yamanashi Pref., Japan, host: unisexual gall of Andricus mukaigawae (Mukaigawa) on Quercus serrata THUNB., 1951 (em. VVI. 1952) (H. MASUDA), KPU No. 277. Paratypes: 24 우, same data as for the holotype; 1 우 $2 \delta^{\lambda}$, Mt. Haruna (alt.: 1,000 m), Gunma Pref., Japan, host: gall of Andricus targionii KIEFFER on Quercus dentata Thunb., 30. X. 1984 (em. I. 1985, under room temperature) (Y. AвE); 25 우 $15 \delta^{\lambda}$, same locality, host and collector, 5. IV. 1985 (em. late April 1985); 2 우, same locality, host and collector, 2. IV. 1986 (em. late April 1986); 22 ㅇ 8 ठ , same locality, host and collector, 29. III. 1995 (em. 26. IV-10. V. 1995); 4 우 1 万 , Hongcheon (alt.: 200-500 m), Kangweon-do, Korea, same host, 8. XI. 1983 (em. 4-8. V. 1984) (K. MORIMOTO and C.Y. LEE).

Distribution. Japan and Korea.

Etymology. This species is named in honor of Mr.

${ }^{1}$ Appl. Entomol. Zool. 32 (1): 253-255 (1997) 

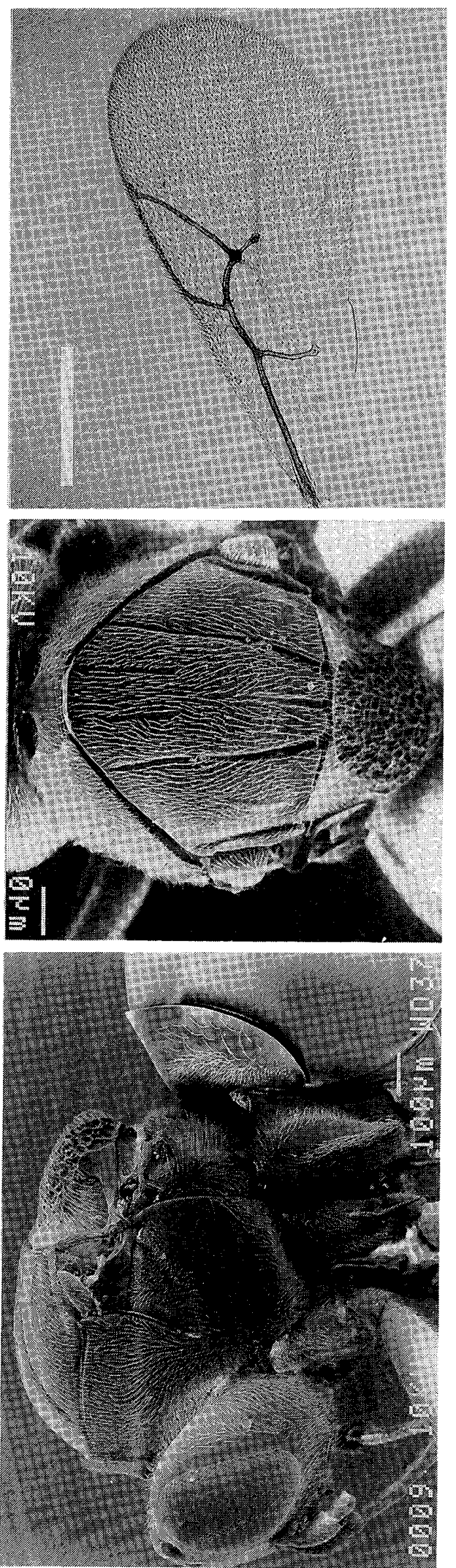

H. MASUdA, who elucidated the biology of the unisexual population of this inquiline gall wasp in Makioka.

Remarks. This is the first record of the genus Ceroptres from Japan and Korea. AsHmeAD (1904) described Ceroptres japonicus from Japan, but this species was transferred to the genus Euceroptres by WELD (1926).

C. masudai and C. clavicomis HARTIG can be distinguished from other members of the genus Ceroptres by a combination of the following four character states: 1) females and males have 12-segmented and 15-segmented antennae, respectively; 2) two vertical carinae on the face are distinct; 3) the mesopleura have no striations; 4) post-dorsal portion of the third metasomal tergite has small punctures. However, $C$. masudai can be distinguished from $C$. clavicornis by the following two character states: 1) C. masudai has anterior parallel and lateral lines on the mesoscutum, unlike $C$. clavicomis; 2) the subalar depression and lower $1 / 3$ of the mesopleuron are pubescent in C. masudai, but the mesopleuron is almost bare and polished in C. clavicomis

BELIZIN (1973) described Ceroptres kovalevi from Primorskiy, Russia. C. kovalevi does not have two vertical carinae on the face, so that $C$. kovalevi and $C$. masudai are easily separable from each other.

\section{ECOLOGICAL NOTES}

\section{Life cycle and inquilinism}

The Andricus mukaigawae complex consists of the bivoltine heterogonic species $A$. mukaigawae and the univoltine thelytokous $A$. targionii; unisexual adults of the former are hardly distinguishable from those of the latter (ABE, 1986). Unisexual galls of $A$. mukaigawae appear in early summer and those of $A$. targionï do so in late spring (ABE, 1986). Only females of $C$. masudai have been obtained from the unisexual galls of $A$. mukaigawae, while females and males occur in the $A$. targionï galls. The biology of the unisexual population of C. masudai in Makioka, described by MASUDA (1959), can be summarized as follows. This population is univoltine and thelytokous. Adult emergence of $C$. masudai from the host galls starts in late May and lasts until early June, almost the time of appearance of the unisexual galls of $A$. mukaigawae. The adults of C. masudai oviposit into young $A$. mukaigawae galls. After oviposition, these galls remain small (diameter: 3$5 \mathrm{~mm}$ ), though the diameter of normal galls increases. Adults of $A$. mukaigawae fail to emerge from galls which have been attacked by $C$. masudai. Each 
gall has one larval chamber containing a single $C$. masudai.

The emergence date of the paratypes indicates that the adults of the two bisexual populations of $C$. masudai from $\mathrm{Mt}$. Haruna and Hongcheon emerge at the time when the $A$. targionii galls begin to appear. Probably, the bisexual populations of $C$. masudai which depend on $A$. targionii galls are also univoltine.

On 29 March 1995, I collected galls produced by A. targionii on $Q$. dentata from $\mathrm{Mt}$. Haruna and maintained them at $18^{\circ} \mathrm{C}$, under a $15 \mathrm{~L}: 9 \mathrm{D}$ photoregime. Adults of $C$. masudai emerged from late April to midMay of that year. I dissected $10 \mathrm{~A}$. targionii galls from which adults of $C$. masudai had emerged, and found one empty larval chamber in each gall. MASUDA (1959)'s and my observations indicate that the young larvae of the $A$. mukaigawae complex are killed by $C$. masudai and then the latter occupy the host galls.

Courtship behaviour

The unisexual population of $C$. masudai is distributed in Makioka and the bisexual populations are distributed in Mt. Haruna and Hongcheon. Mt. Haruna and Hongcheon are located further north than Makioka. Males of a cynipid, Diplolepis rosae (L.), are rare, but more abundant in the north of England (Askew, 1959); they do not perform any courtship behaviour, even if they are confronted with conspecific females (ADLER, 1877). Similarly, males of Diplolepis japonica (WALKER) are rare and do not show interest in conspecific females (Yasumatsu and TAKETANI, 1967). Thus, I investigated whether or not males of $C$. masudai show courtship behaviour when confronted with conspecific females. Some of the $C$. masudai emerging from $A$. targionii galls during the observations described in the previous section were used for this purpose in April and May 1995.

Under laboratory conditions $\left(20^{\circ} \mathrm{C}\right)$, I made two observations of the courtship behaviour of $C$. masudai. First, one adult virgin female and one adult virgin male, within $24 \mathrm{~h}$ after emergence from two galls were put into a $10 \mathrm{ml}$ glass vial. The virgin male walked about the vial and chased the virgin female. He mounted her back, moved his antennae alternately and tapped her face and antennae for $41 \mathrm{~s}$. During this period, wing vibration occurred 8 times, inconstantly. The female stood motionless and he stopped stroking his antennae and walked backwards a few steps on her. Then he bent his abdomen and copulated. The duration of genital contact was $18 \mathrm{~s}$. Second, two pairs consisting of a 2-day-old oncecopulated female and a 1-day-old virgin male were observed similarly. Each virgin male chased the oncecopulated female, mounted her, and stroked his antennae. The duration of mounting and the number of wing vibrations were $70 \mathrm{~s}$ and 13 , and $40 \mathrm{~s}$ and 11 , respectively. After stroking his antennae, each male bent his abdomen to copulate, but neither female accepted him. A previous study (ABE, 1991) indicated that once-copulated females of another inquiline gall wasp, Synergus japonicus WALKER, do not copulate again during their entire life time. This is possibly the case with $C$. masudai. The present observations confirmed that males of $C$. masudai perform courtship behaviour and copulate with females, unlike those of D. rosae and japonica.

Mode of reproduction

MAsuda (1959) reported that the unisexual population of $C$. masudai in Makioka reproduces thelytokously. He (1996) summarized the biology of this species under the name Synergus sp. and mentioned that only female wasps emerged from 200 galls examined. On the other hand, male wasps of $C$. masudai have been collected on Mt. Haruna and in Hongcheon; they are not rare and can copulate with females in Mt. Haruna population. Though $C$. masudai is known from only three localities, there exists the possibility that geographic parthenogenesis occurs in this wasp. Further investigation is needed to clarify the mode of reproduction in the bisexual population of C. masudai.

\section{REFERENCES}

AвE, Y. (1986) Appl. Entomol. Zool. 21: 436-447.

AвE, Y. (1991) J. Appl. Entomol. 111: 478-483.

ADler, H. (1877) . Dt. Entomol. Z. 21: 209-248.

ASHMEAD, W.H. (1904) J. N. Y. Entomol. Soc. 12: 6584.

Askew, R.R. (1959) Entomol. Month. Mag. 95: 191192.

Belizin, V.I. (1973) Entomol. Obozr. 52: 29-38 (in Russian; transl. in Entomol. Rev. 52: 18-24).

Masuda, H. (1959) In Nihon-Kontyu-Ki, Vol. III (K. Iwata, H. Furukawa and K. Yasumatsu, eds.). Kodan-sha, Tokyo, pp. 103-138 (in Japanese).

Masuda, H. (1996) Insect and Mite Galls of Japan in Colors (J. YukawA and H. MASUdA, eds.). ZenkokuNouson-Kyoukai, Tokyo, 826 pp. (in Japanese).

Ronquist, F. (1994) Evolution 48: 241-266.

WELD, L.H. (1926) Proc. U.S. Nat. Mus. 68(10): $1-$ 131,8 pls.

Yasumatsu, K. and A. TAKetani (1967) Esakia 6: 77-86, 4 pls. 